\title{
A New Neutron Beam Facility at TSL
}

\author{
Alexander V. Prokofiev *, Olle Byström, Curt Ekström, Volker Ziemann \\ The Svedberg Laboratory, Uppsala University \\ Box 533, S-751 21 Uppsala, Sweden \\ E-mail: Alexander.Prokofiev@tsl.uu.se
}

Jan Blomgren, Stephan Pomp, Michael Österlund

Department of Neutron Research, Uppsala University

Box 525, S-751 20 Uppsala, Sweden

E-mail: Jan.Blomgren@tsl.uu.se

\section{Udomrat Tippawan}

Fast Neutron Research Facility, Chiang Mai University

50202 Chiang Mai, Thailand

E-mail: Udomrat@fnrf.science.cmu.ac.th

A new quasi-monoenergetic neutron beam facility has been constructed at The Svedberg Laboratory (TSL) in Uppsala, Sweden. Key features include a neutron energy range of 11 to 175 $\mathrm{MeV}$, high fluxes, user flux control, flexible neutron field size and shape, and spacious and easily accessible user area. The first results of the beam characterization measurements are reported.

International Workshop on Fast Neutron Detectors

University of Cape Town, South Africa

April 3-6, 2006

\section{${ }^{*}$ Speaker}




\section{Introduction}

The interest in high-energy neutrons is rapidly growing, since a number of potential largescale applications involving fast neutrons are under development, or have been identified. These applications primarily fall into four sectors: nuclear energy and waste [1], medicine [2, 3], flight personnel dosimetry [4], and single-event effects (SEE) on electronics [5, 6].

To satisfy the needs of these applications, monoenergetic neutron beams would be most suitable. In the energy region above about $20 \mathrm{MeV}$, a truly monoenergetic neutron beam is not feasible in a strict sense. For certain nuclear reactions, however, there is a strong dominance of neutrons in a narrow energy range. Therefore, such neutron sources are often called "quasimonoenergetic". The most popular neutron production reaction above $20 \mathrm{MeV}$ is ${ }^{7} \mathrm{Li}(\mathrm{p}, \mathrm{n}){ }^{7} \mathrm{Be}$. It is used, e.g., at quasi-monoenergetic neutron facilities in Cape Town [7], Davis [8], Louvain-laNeuve [9], Saitama [10], and Takasaki [11].

There is a long-term experience in high-energy neutron production at The Svedberg Laboratory (TSL). The first neutron facility was built at TSL in the late 1980s $[12,13]$ and remained in operation until 2003. In 2003-2004, a new facility was constructed. Emphasis was put on high neutron beam intensity in combination with flexibility in energy and neutron field shape.

\section{Technical specification}

The facility uses the ${ }^{7} \mathrm{Li}(\mathrm{p}, \mathrm{n})^{7} \mathrm{Be}$ reaction to produce a quasi-monoenergetic neutron beam. Two kinds of beams from the Gustaf Werner cyclotron are used for neutron production: 1) proton beam with energy variable in the $25-180 \mathrm{MeV}$ range, and, 2) beam of $\mathrm{H}_{2}{ }^{+}$ions with energy of about $13 \mathrm{MeV} / \mathrm{A}$. The energy of the produced peak neutrons is controllable in the 11-175 MeV range.

A drawing of the neutron beam facility is shown in Fig. 1. The proton or $\mathrm{H}_{2}{ }^{+}$beam is incident on a target of lithium, enriched to $99.99 \%$ in ${ }^{7} \mathrm{Li}$. The available targets are 1, 2, 4, 8.5, and $23.5 \mathrm{~mm}$ thick. Proton energy loss in the target amounts to 2-6 MeV depending on the incident beam energy and target thickness. The targets are rectangular in shape, $20 \times 32 \mathrm{~mm}^{2}$, and are mounted in a remotely controlled

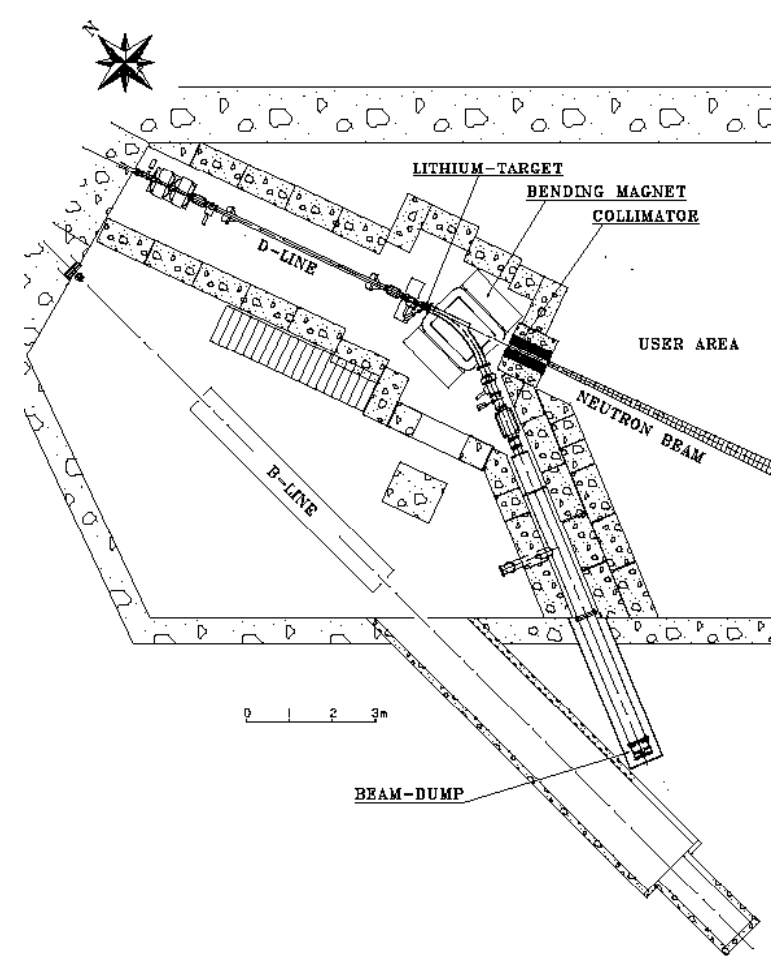

Fig. 1. Drawing of the new neutron beam facility. The neutron beam, produced in the lithium target, continues along the D-line. 
water-cooled copper rig. An additional target position contains a fluorescent screen viewed by a TV camera, which is used for beam alignment and focusing. Downstream the target, the proton beam is deflected by a magnet into a $10-\mathrm{m}$ long dumping line, where it is guided onto a heavily shielded water-cooled graphite beam dump.

The neutron beam is formed geometrically by a cylindrically shaped iron collimator block, $50 \mathrm{~cm}$ in diameter and $100 \mathrm{~cm}$ long, with a hole of variable size and shape. The collimator is surrounded by concrete to form the end wall of the production line towards a user area. Thereby, shielding from the lithium target region is achieved that is sufficient for most experiments. A modular construction of the collimator allows the user to select the size and the shape of the neutron beam. At present, the available collimator openings are 2, 3, 5.5, 10, 15, 20, and $30 \mathrm{~cm}$ in diameter. In addition, a quadratically shaped opening of $1 \mathrm{~cm}^{2}$ is available, which is intended for irradiation of, e.g., a separate electronic component without affecting the rest of an electronic board. Other collimator openings in the $0-30 \mathrm{~cm}$ range can be provided upon request. The time needed to change the opening size is typically about $30 \mathrm{~min}$.

The user area extends from 3 to $15 \mathrm{~m}$ downstream the lithium target. Positions located closest to the target are used for high-flux irradiation of compact objects, with achievable fluxes about an order of magnitude higher compared to the old TSL neutron facility [12, 13], for the same target thickness, proton energy and current. Remote positions may be used to irradiate large objects, up to $1 \mathrm{~m}$ in diameter, e.g., entire computers or aircraft navigation systems. Proton beam currents of up to $10 \mu \mathrm{A}$ can be used for energies below $100 \mathrm{MeV}$. Above $100 \mathrm{MeV}$, the achievable beam current is about a factor of 10 lower. The resulting reduction of the neutron flux can be partly compensated by using thicker lithium targets. The neutron flux can be varied by the user according to the needs of the specific experiment.

The user area, situated at a level of $12 \mathrm{~m}$ below the ground, is connected by Ethernet and coaxial cables, about $100 \mathrm{~m}$ long, to counting rooms, which are located at the ground level. No time is required for "cooling down" of the user area after irradiation, because the dose rate from residual $\beta$ - and $\gamma$-rays is then only slightly above the natural radiation level.

Two additional irradiation positions, which can be used parasitically with other experiments, are provided closer to the lithium target (see Table I). The increase of the neutron flux at these positions is reached at the expense of limited accessibility, limited size of irradiated objects, lack of standard monitors, and

\begin{tabular}{|lccc|}
\hline \multicolumn{4}{|c|}{ Table I. Parasitic irradiation positions. } \\
\hline Position & $\begin{array}{c}\text { Distance } \\
\text { from the } \\
\text { Li target } \\
(\mathbf{m})\end{array}$ & $\begin{array}{c}\text { Angle to } \\
\text { the proton } \\
\text { beam } \\
\text { direction } \\
\left({ }^{\circ}\right)\end{array}$ & $\begin{array}{c}\text { Gain in the } \\
\text { peak } \\
\text { neutron flux }\end{array}$ \\
\hline PARTY & 1.9 & 1.6 & 2.5 \\
TUNIS & 1.1 & 7.5 & $1.7-2.2^{\mathrm{a})}$ \\
\hline a) dependent on the peak neutron energy. \\
\hline
\end{tabular}
more intense $\gamma$-ray background. 


\section{Characterization of the facility}

Neutron spectra at $0^{\circ}$ have been obtained by measuring elastic $n p$-scattering with the Medley setup [14-16]. The scattered protons are registered at an angle of $20^{\circ}$ relative to the neutron beam. The measured neutron spectra are shown in Fig. 2 for peak energies of 21.8 (a), 46.5 (b), 94.7 (c), and $142.7 \mathrm{MeV}$ (d). In all cases, the spectrum is dominated by a peak situated a few $\mathrm{MeV}$ below the energy of the primary protons and comprising about $40 \%$ of the total number of neutrons.

Fig. 2 includes a comparison of the measurements with model calculations of the neutron spectra folded with the function that describes the energy resolution in the present experiment. For the three higher energies (Fig. 2b-d), the systematics of Prokofiev et al. [17] was employed. For the peak neutron energy of $21.8 \mathrm{MeV}$, the evaluation of Mashnik et al. [18] was used (Fig. 2a). The differential crosssection for high-energy peak neutron production at $0^{\circ}$ was obtained by multiplication of the angle-integrated crosssection of the ${ }^{7} \mathrm{Li}(\mathrm{p}, \mathrm{n})^{7} \mathrm{Be}$ reaction [18] to the "index of forwardness" from the systematics of Uwamino et al. [19]. The experimental data agree with the calculations except for the lowenergy tail region in the $21.8 \mathrm{-MeV}$ spectrum where the model overpredicts the yield of neutrons with energies above $5 \mathrm{MeV}$ by about $40 \%$.

Table II summarizes the main features of the measured spectra and the achieved neutron fluxes. The latter have been measured with a monitor based on a thin-film breakdown counter (TFBC) [20]. Another monitoring option is provided by an ionization-chamber monitor (ICM). Both monitors utilize neutron-induced fission of ${ }^{238} \mathrm{U}$ with the cross-section adopted as neutron flux standard [21]. In addition, the neutron flux is indirectly monitored by a Faraday cup, which integrates the current of protons collected at the beam dump. In Table II, $\gamma$-ray dose rate in the user area is given as well.

The measured contamination of the neutron beam at the user area, due to interactions of the primary protons with beam transport elements, typically does not exceed $0.05 \%$ for peak neutron energies up to $100 \mathrm{MeV}$ and $0.3 \%$ for the $174 \mathrm{MeV}$ energy. Such interactions lead to a minor surplus of neutrons in the user area, because charged particles produced near the lithium target and upstream are removed by the deflection magnet. The relative contamination of the 
neutron beam by protons with energies above 15 $\mathrm{MeV}$ is about $10^{-5}$ for the peak neutron energy of $95 \mathrm{MeV}$.

Thermal neutrons were found in the user area, using TFBCs with ${ }^{235} \mathrm{U}$ targets, shielded by a cadmium sheet during a part of the runs. The thermal neutron flux was estimated to be about $1 \%$ of the peak neutron flux at $174 \mathrm{MeV}$ energy [22]. This result comes from an ongoing systematic study of the low-energy part of the neutron spectra using TFBCs and different neutron-induced fission reactions.

Figure 3 shows a horizontal beam profile for $142.7-\mathrm{MeV}$ neutrons, measured at a distance of $4.77 \mathrm{~m}$ from the lithium target. The measurement was performed by counting neutron-induced SEE in a set of memory chips positioned across the beam [23].

\section{Summary and outlook}

A new neutron beam facility has been constructed at TSL, and it is in frequent operation now ( 25 weeks during year 2005). The facility is capable of delivering neutrons in the 11-175 MeV range. This makes TSL the only laboratory in the world offering full quasimonoenergetic neutron testing according to the JESD89 standard [6].

Recently, a neutron field with the peak energy of about $11 \mathrm{MeV}$ has been developed. Processing of neutron spectra at 11 and $174 \mathrm{MeV}$ is in progress. A fast ionization chamber for regular checks of the neutron spectrum is under development [24]. An additional neutron

Table II. Neutron beam parameters.

\begin{tabular}{|c|c|c|c|c|c|c|c|}
\hline \multirow[t]{2}{*}{$\begin{array}{l}\text { Proton } \\
\text { beam } \\
\text { energy } \\
(\mathrm{MeV})\end{array}$} & \multirow{2}{*}{$\begin{array}{l}{ }^{7} \mathbf{L i} \\
\text { target } \\
\text { thick- } \\
\text { ness } \\
(\mathrm{mm})\end{array}$} & \multirow[t]{2}{*}{$\begin{array}{c}\text { Proton } \\
\text { beam } \\
\text { current } \\
(\mu \mathrm{A})\end{array}$} & \multirow{2}{*}{$\begin{array}{l}\text { Average } \\
\text { energy of } \\
\text { peak } \\
\text { neutrons } \\
(\mathrm{MeV})\end{array}$} & \multicolumn{2}{|c|}{$\begin{array}{c}\text { Fraction of } \\
\text { neutrons in the } \\
\text { high-energy } \\
\text { peak }(\%)\end{array}$} & \multirow{2}{*}{$\begin{array}{c}\text { Peak } \\
\text { neutron } \\
\text { flux } \\
\left(10^{5}\right. \\
\left.\mathrm{cm}^{-2} \mathrm{~s}^{-1}\right) \\
\text { a) }\end{array}$} & \multirow[t]{2}{*}{$\begin{array}{c}\gamma \text {-ray } \\
\text { dose rate } \\
(\mathrm{mSv} / \mathrm{h}) \\
\text { b) }\end{array}$} \\
\hline & & & & $\begin{array}{l}\text { Meas- } \\
\text { ured }\end{array}$ & $\begin{array}{l}\text { Calc- } \\
\text { ulated }\end{array}$ & & \\
\hline $24.68 \pm 0.04$ & 2 & 10 & 21.8 & $\sim 50$ & -- & 1.3 & 0.35 \\
\hline $49.5 \pm 0.2$ & 4 & 10 & 46.5 & 39 & 36 & 2.9 & 1.7 \\
\hline $97.9 \pm 0.3$ & 8.5 & 5 & 94.7 & 41 & 39 & 4.6 & 2.4 \\
\hline $147.4 \pm 0.6$ & 23.5 & 0.6 & 142.7 & $\left.55^{c}\right)$ & 40 & 2.1 & - \\
\hline
\end{tabular}

a) At the entrance of the beam line to the user area.

b) At the neutron beam path at the distance of $8 \mathrm{~m}$ from the lithium target.

c) Upper limit due to poor energy resolution.

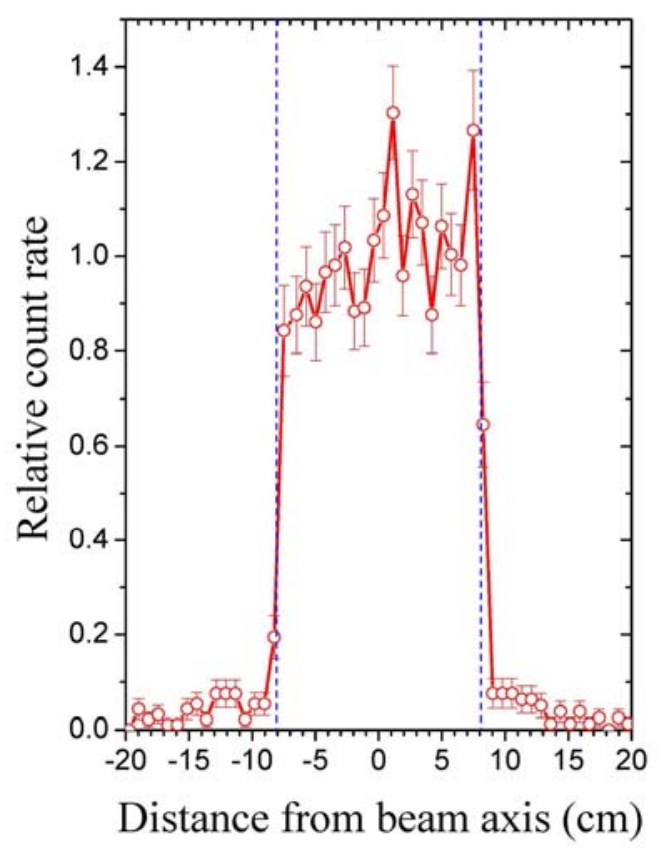

Fig. 3. The horizontal beam profile for $142.7-\mathrm{MeV}$ neutrons, measured at the istance of $4.77 \mathrm{~m}$ from the lithium target. of the beam expected from the geometry of the collimator. 
monitor based on counting of neutron-induced SEE is about to be installed [25]. Independent calibrations of neutron monitors are planned, using measurements of the ${ }^{7} \mathrm{Be}$ activity produced in the ${ }^{7} \mathrm{Li}$ target, following a technique suggested by Uwamino et al. [19].

A new upgrade of the facility is being launched in the framework of project ANITA (Atmospheric-like Neutrons from thIck TArget). The upgrade will allow us to deliver a neutron beam with a continuous "white" spectrum, and thus to reproduce the spectrum of neutrons in the atmosphere. Neutrons will be produced by irradiation of a thick tungsten target by high-energy protons. The possibility to deliver quasi-monoenergetic neutron beams will be kept.

\section{Acknowledgements}

We would like to thank all the staff at The Svedberg Laboratory for the excellent work in building this new facility. We are thankful to A.N. Smirnov and M. Olmos for providing us with the thermal neutron data and the beam profile data, respectively.

\section{References}

[1] A. Koning, et al., J. Nucl. Sci. Technol. 2, 1161 (2002).

[2] R. Orecchia, et al., Eur. J. Cancer 34, 459 (1998).

[3] D. L. Schwartz, et al., Int. J. Radiat. Oncol. Biol. Phys. 50, 449 (2001).

[4] D. T. Bartlett, et al., Radiat. Res. Congress Proceedings 2, 719-723 (2000).

[5] Single-Event Upsets in Microelectronics, topical issue, edited by H. H. K. Tang and N. Olsson [Mater. Res. Soc. Bull. 28 (2003)].

[6] JEDEC Standard. Measurements and Reporting of Alpha Particles and Terrestrial Cosmic RayInduced Soft Errors in Semiconductor Devices. JESD89, August 2001.

[7] R. Nolte, et al., Nucl. Instrum. Meth. Phys. Res. A 476, 369 (2002).

[8] F.P. Brady, Can. J. Phys. 65, 578 (1987).

[9] H. Schuhmacher, et al., Nucl. Instrum. Meth. Phys. Res. A 421, 284 (1999).

[10] N. Nakao, et al., Nucl. Instrum. Meth. Phys. Res. A 420, 218 (1999).

[11] M. Baba, et al., Nucl. Instrum. Meth. Phys. Res. A 428, 454 (1999).

[12] H. Condé, et al., Nucl. Instrum. Meth. Phys. Res. A 292, 121 (1990).

[13] J. Klug, et al., Nucl. Instrum. Meth. Phys. Res. A 489, 282 (2002).

[14] S. Dangtip, et al., Nucl. Instrum. Meth. Phys. Res. A 452, 484 (2000).

[15] S. Pomp, et al., AIP Conf. Proc. 769, 780-783 (2005).

[16] S. Pomp, et al., these proceedings

[17] A.V. Prokofiev, et al., J. Nucl. Sci. Techn., Suppl. 2, 112 (2002).

[18] S.G. Mashnik, et al., LANL Report LA-UR-00-1067 (2000).

[19]Y. Uwamino, et al., Nucl. Instrum. Meth. Phys. Res. A 389, 463 (1997).

[20] A.N. Smirnov, et al., Radiat. Meas. 25, 151 (1995).

[21] A.D. Carlson, et al., Proc. Int. Conf. on Nuclear Data for Science and Technology, Trieste, Italy, May 19-24, 1997, Part II, p. 1223.

[22] A.N. Smirnov, private communication.

[23] M. Olmos, private communication.

[24] I.V. Ryzhov, private communication.

[25] R. Harboe-Sorensen, private communication. 